\title{
A Compare of Fuzzy Logic and Entropy Models: A Case Study of Assessment Analysis of Geohazard Susceptibility in Jianshi County of Qingjiang River Basin
}

\author{
Ningtao Wang ${ }^{1, *}$, Tingting $\mathrm{Shi}^{2}, \mathrm{Ke} \mathrm{Peng}^{1}$, Zhipeng $\mathrm{Lian}^{1}$, Yiyong $\mathrm{Li}^{1}$, Qing \\ Wang $^{1}$, Wen Chen ${ }^{1}$ and Bolin Huang ${ }^{1}$ \\ ${ }^{1}$ Wuhan Center of Geological Survey, 69 Guanggu Road, Wuhan 430502, \\ People's Republic of China \\ ${ }^{2}$ Three Gorges Research Center for Geohazard, Ministry of Education, China \\ University of Geosciences, 388 Luomo Road, Wuhan 430074, People's Republic \\ of China \\ wnt113@126.com
}

\begin{abstract}
Fuzzy logic model and entropy model are useful for the geohazard susceptibility zonation in Jianshi County of Qingjiang River Basin. In this paper, the same impact factors were chosen and the geohazard samples were considered in two cases with quantitative analysis method. The first case 162 geohazards chosen as samples and the other one all of 182 geohazards chose as samples. The authors completed the susceptibility zonation in the two different cases using the two models in order to analysis the effects of the two models. The results of the two models in different cases were almost the same in space, except small differences in some areas. The entropy model was more accurate for the analysis of relationship between impact factors and geohazards, but not stable for different geohazard samples. The fuzzy logic model was better for less geohazard samples. According to the analysis process, it was found that the fuzzy $\gamma$ operation was the best which was defined in terms of the fuzzy algebraic product and the fuzzy algebraic sum. The results of fuzzy logic model were most useful when $\gamma$ was 0.20. The fuzzy logic model and entropy model were useful for the geohazard susceptibility which was scientific and useful for the government to manage the geohazards and make the preliminary development plans.
\end{abstract}

Keywords: Fuzzy logic model; entropy model; geohazards susceptibility; quantitative analysis; GIS

\section{Introduction}

In the $21^{\text {st }}$ century, most of researches on geohazards susceptibility used different statistics or logic methods with GIS (Geographical Information System) technology [1-6]. The geohazard susceptibility could be calculated by the probability of geohazard occurrence in space over a background of geo-environmental conditions. The analysis aim has been transitted from qualitative analysis to quantitative analysis. Many methods and techniques were used to estimate the geohazard susceptibility in order to get an accuracy result, such as statistical methods based on the physical and classification models [5-9].

In recent years, with the development of GIS technology, the researchers focused on the quantitative analysis on basis of some physical and conceptual model to build mathematical model in order to improve the accuracy [5-10]. There were many

* Corresponding author: Wuhan Center of Geological Survey, 69 Guanggu Road, Wuhan 430502, People's Republic of China. Current contact: Tel.: +86-027-81381850,E-mail: wnt113@126.com 
quantitative analysis methods, including entropy model, evidential belief functions, fuzzy logic model, likelihood ratio, logistic regression and artificial neural network models and so on. Some methods had been applied in different areas on basing of the probability and numerical statistics to make the degree of disorder impact factors into a system $[5,9,11$ 12] In this paper, entropy model and fuzzy logic model were selected to complete the geohazard susceptibility zonation and compare the two methods with each other in order to find out the advantages and disadvantages in each method.

Entropy model had been applied in different fields. The applications of entropy have focused on water management, energy utilization, landscape analysis, urban ecosystem and the quality of economic growth [13-15]. The entropy approach was beginning to apply in the geosciences in recent years. Some experts used the entropy approach to analysis geological data in order to obtain more accurate and scientific results [11, 16-22]. It is a good method to analyze the susceptibility of geohazards according to the mass data investigated to get more information and connection with different impact factors.

Fuzzy logic model was introduced by Zadeh [23] and had been used to many fields due to the advantages of analyzing disorder natural process or phenomena with mathematical methods. On basis of the characters, the different classes of impact factors graded can be characterized by a membership function which assigns to each object a grade of membership ranging between zero and one. The spatial objects on a map are considered as members of each impact factor in geohazard susceptibility mapping [24-26]. Generally, the different impact factors could be quantified according to the occurrences of geohazards in each impact factor. On basis of the characters, the fuzzy logic model could be used to complete the geohazard susceptibility zonation according to the probability of occurrences with statistical methods depending on spatial and mathematical characters.

In this paper, according to the field investigation data, quantitative analysis calculation was made by the entropy and fuzzy logic models with GIS technology. On basis of the results of the two models, the advantages and disadvantages would be found out. It can provide a reference to the formation mechanism of geohazard and estimation of geohazard susceptibility in the future $[2-4,18,23,27]$.

\section{Study Area and Data}

\subsection{Study Area}

Jianshi County is located in the Qingjiang River Basin, the Center of China. The study area is about $2667 \mathrm{~km}^{2}$ and extends from latitude $30^{\circ} 01^{\prime}$ to $30^{\circ} 56^{\prime}$ North and from longitude $109^{\circ} 30^{\prime}$ to $110^{\circ} 10^{\prime}$ East (Figure 1). The landscape is tectonic erosion corrosion middle-mountain and low-middle-mountain. In this area, the geological features and conditions are extremely complex, which are characterized by steep mountains, crisscross ravines, about the difference of $1877 \mathrm{~m}$ and an average slope of $25^{\circ}$. The weather is dry in winter and wet in summer, which is influenced by the subtropical monsoon climate. Human engineering activities are frequent in Jianshi County. There are several large projects, such as Shuibuya Project in Qingjiang River, Yi-wan Railway, Hu-rong High Way and Natural Gas Pipe and so on. These projects lead to a large number of immigrants and reconstruction which are followed by unreasonable engineering site, road cut slope, blasting vibration, the excavation and mining, et al. The human activities aggravate the occurrences of geohazard further. 


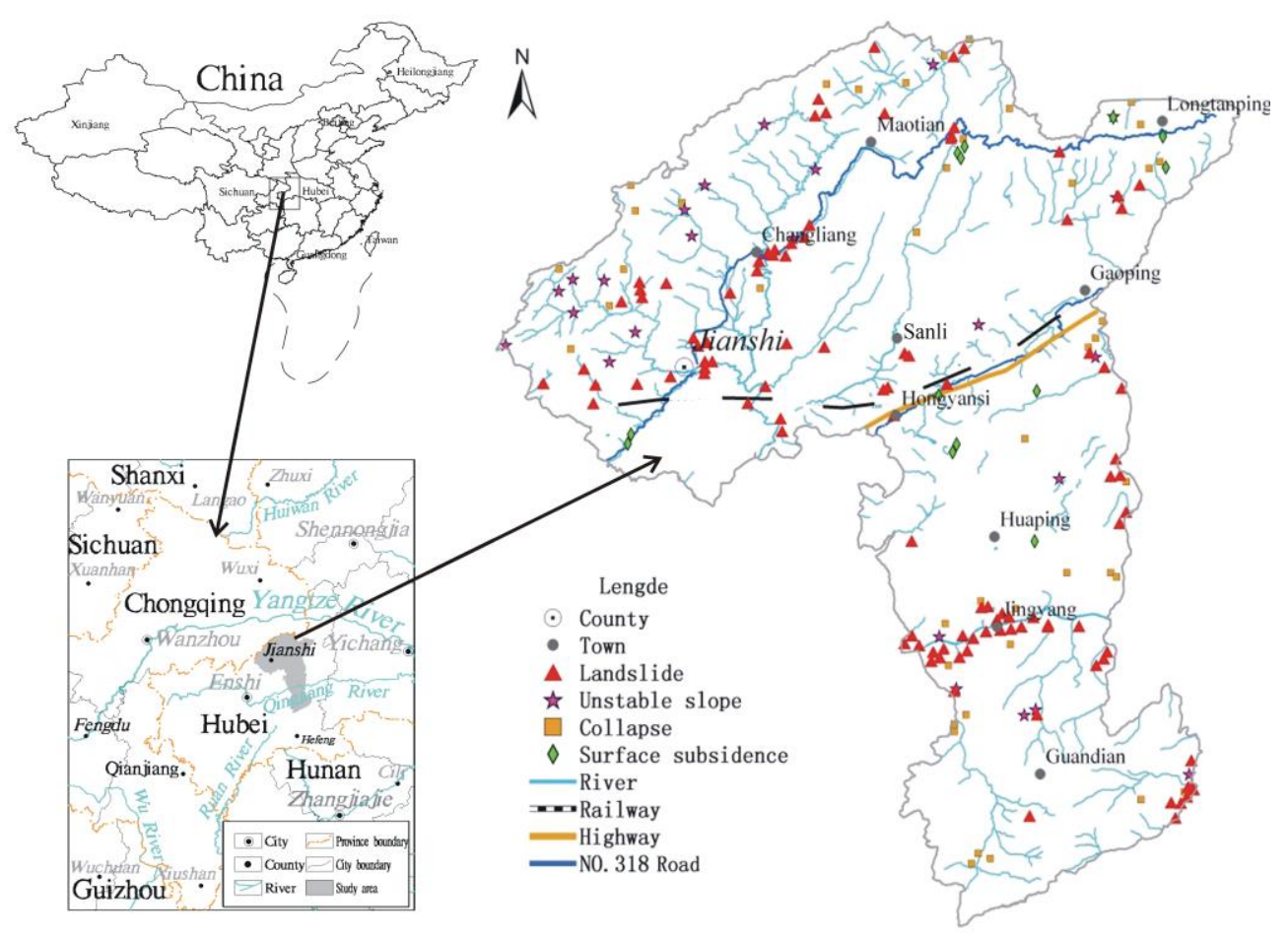

Figure 1. Positions and Types of Geohazards in Jianshi County

Due to the special natural, geographical environment, geological formation and the human engineering activities, geohazards develop in this county, mainly landslides, collapse and unstable slopes. The positions and types of geohazards are given in Figure 1. In the study area, the total number of geohazards is 182, including 102 landslides, 43 collapses (including unstable rocks), 24 unstable slopes and 13 surface subsidences. Collapse and landslide are dominant geohazard.

\subsection{Data Selection}

According to previous studies [3-6, 12, 18, 23, 28-31], combined with the actual situation in Jianshi County, seven individual factors were selected as the geohazards susceptibility zoning control factors, including slope height, slope type, geotechnical engineering rock group type, the distance from river or valley, geological structural conditions and human engineering activities impacts.

In order to complete the susceptibility zonation, the basic data were mainly collected and from field survey (hydro-geological maps, engineering geological maps, geographic traffic maps and remote sensing data). Most data were collected from the projection "Qingjiang River Basin Geological Disasters Detailed Survey", and others were from the field survey. Some data of Jianshi County was in Table 1. The scopes of geohazards were extracted from the remote sensing imageries. The total projection area of geohazards was about $1.8480 \mathrm{~km}^{2}$.

Table 1. Data of Study Area

\begin{tabular}{l|l|l|l|l|l}
\hline \multicolumn{1}{c|}{ Data } & \multicolumn{1}{|c|}{ Scale } & \multicolumn{1}{|c}{ Date } & \multicolumn{1}{c}{ Data } & \multicolumn{1}{c}{ Scale } & \multicolumn{1}{c}{ Date } \\
\hline Engineering geological map & $1: 50000$ & 2010 & P6 & $5.8 \mathrm{~m}$ & April 13, 2008 \\
\hline Geohazards distribution map & $1: 50000$ & 2010 & ALOS & $2.5 \mathrm{~m}$ & June 17,2009 \\
\hline Geographic map & $1: 50000$ & 2000 & ASTER & $15 \mathrm{~m}$ & July 5, 2008 \\
\hline Traffic and location map & $1: 100000$ & 2010 & Geology map & $1: 200000$ & 1978 \\
\hline
\end{tabular}




\section{Methodology}

\subsection{Entropy Model}

Entropy model was used to carry out quantitative analysis based on the contribution of influential factors on the formation of geohazards by calculating their contributions to the geohazard failure to determine the damage of such factors on the geohazards' bodies. This would not only reflect the statistical laws of geohazards, but also could be performed simply and easily $[3-4,11-12,18-21,23,32-33]$. The calculation principle and the process are shown in the equations below.

In this model, the occurrence of geohazards was considered to be related to both quantity and quality of information that is obtained in the process of forecast, and shall be measured based on the information entropy model, namely:

$$
I\left(Y, x_{1}, x_{2}, x_{3} \ldots x_{n}\right)=\operatorname{In} \frac{P\left(Y, x_{1}, x_{2}, x_{3} \ldots x_{n}\right)}{P(Y)}
$$

where: $I\left(Y, x_{1}, x_{2}, x_{3}, \ldots, x_{n}\right)$ mean the information entropy provided by factors combination $x_{1}, x_{2}, x_{3}, \ldots, x_{n}$ for geohazards, $P\left(Y, x_{1}, x_{2}, x_{3}, \ldots, x_{n}\right)$ mean the probability of geohazards under the conditions of factors combination $x_{1}, x_{2}, x_{3}, \ldots, x_{n}, P(Y)$ mean the probability of geohazards.

According to conditional probability operation, equation (1) could be further calculated as:

$$
P\left(Y, x_{1}, x_{2}, x_{3} \ldots x_{n}\right)=I\left(Y, x_{1}\right)+I_{x_{1}}\left(Y, x_{2}\right)+\cdots+I_{x_{1}, x_{2}, x_{3} \ldots x_{n-1}}\left(Y, x_{n}\right)
$$

where: $I_{x I}\left(Y, x_{2}\right)$ mean the information entropy provided by factor $\mathrm{x}_{2}$ with the existence of factor $x_{1}$.

The establishment process of information entropy model was as follows:

i) Calculation of the information entropy value $I\left(x_{i} \mid H\right)$ provided by factor $x_{i}$ for the geohazards event $(\mathrm{H})$, namely:

$$
I\left(x_{i} \mid H\right)=\operatorname{In} \frac{P\left(x_{i} \mid H\right)}{P\left(x_{i}\right)}
$$

where: $P\left(x_{i} \mid H\right)$ mean the probability of factor $x_{i}$ occurrence in the conditional zoning of geohazards, $P\left(x_{i}\right)$ mean the probability of factor $x_{i}$ occurrence in the zone.

Expression (3) was just the theoretical model. Following sample frequency calculation was often used in practice:

$$
I\left(x_{i} \mid H\right)=\operatorname{In} \frac{N_{i} / N}{S_{i} / S}
$$

where: $N_{i}$ mean the number of geohazards units distributed within factor $\mathrm{x}_{\mathrm{i}}, N$ mean the total number of geohazards units distributed within the study area, $S_{i}$ means units number of factor $\mathrm{x}_{\mathrm{i}}$ within the study area, and $S$ mean total number of units within the study area.

ii) Calculation of the total information entropy $I_{i}$ provided by $n$ types of factors within the evaluation units:

$$
I_{i}=\sum_{i=1}^{n} I\left(x_{i}, H\right)=\sum_{i=1}^{n} \operatorname{In} \frac{N_{i} / N}{S_{i} / S}
$$

where: $I_{i}$ mean the total information content of the evaluation units, $\mathrm{n}$ mean the number of influence factors.

iii) Calculation of the total information entropy $I_{i}$, as the aggregative indicator of the evaluation unit in influential the occurrence of geohazards, the larger value it had, the more likely geohazards was to happen, and the higher risk of such geohazards. When $I_{i}$ had a positive value, it would accelerate the geohazards. 
iv) Substituted the calculation results of entropy into the evaluation model and used ArcGIS to carry out spatial analysis calculation to obtain the susceptibility index values of each area.

\subsection{Fuzzy Logic Model}

Fuzzy logic model was based on the frequency ratio, which was calculated according to the membership function. The relationship of fuzzy logic model was not only the spatial but also the quantitative relationship between the geohazards and the impact factors [23-26, 34-35]. The frequency ratio of geohazards could be obtained according to the statistical analysis of the observed geohazards in a certain impact factor. On basis of the frequency ratio, the probability of occurrence of geohazards could be completed by the fuzzy logic operators. The susceptibility zones of geohazards of each area could be obtained by the ArcGIS spatial analysis function according to the probability. The ratio was carried out by the percentages of geohazards in each impact factor and the impact factor in the whole study area.

The frequency ratio was defined as:

$$
W_{i j}=\left(\frac{r_{i j}}{r}\right)=\left(\frac{N_{i j}}{N} \times \frac{S}{S_{i j}}\right)
$$

Where: $\mathrm{W}_{\mathrm{ij}}$ was the frequency ratio of a certain class $\mathrm{I}$ of parameter $\mathrm{j}, \mathrm{r}_{\mathrm{ij}}$ was the geohazard density within class I of parameter $\mathrm{j}, \mathrm{r}$ was the geohazard density within the entire map, $\mathrm{N}_{\mathrm{ij}}$ was the area of geohazards in class I of parameter $\mathrm{j}, \mathrm{S}_{\mathrm{ij}}$ was the area of class I of parameter $\mathrm{j}, \mathrm{N}$ was the total of geohazards in the entire map, and $\mathrm{S}$ was the total area of the entire map.

The frequency ratio was higher; the relationship between geohazard and the factors was higher. Then, the frequency ratio was normalized between 0.00 and 1.00 to create the fuzzy membership value.

$$
f_{i j}=W_{i j} / \max \left(W_{i j}\right)
$$

Where: $\mathrm{f}_{\mathrm{ij}}$ was the fuzzy membership value of class $\mathrm{i}$ of parameter $\mathrm{j}$.

There were five operators in the fuzzy logic model, including fuzzy AND, fuzzy OR, fuzzy algebraic product, fuzzy algebraic sum and the fuzzy $\gamma$ operator.

The fuzzy AND operator was equivalent to a logical intersection operation (Boolean AND), defined as:

$$
f_{\text {and }}=\min \left(f_{a}, f_{b}, f_{c}, \cdots\right)
$$

where: $f$ combination was the combined fuzzy membership function, $f_{a}$ was the membership value for factor a at a particular location, $f_{b}$ was the membership value for factor $b$ at a particular location, etc.

The fuzzy OR was equivalent to the logical union operation (Boolean OR), defined as:

$$
f_{\text {or }}=\max \left(f_{a}, f_{b}, f_{c}, \cdots\right)
$$

The fuzzy algebraic product was defined as:

$$
f_{a p}=\prod_{i=1}^{n} f_{i}
$$

where: $f_{i}$ was the fuzzy membership function of the $i^{\text {th }}$ map and $i=1,2, \ldots, n$ maps were to be combined.

The fuzzy algebraic sum was complementary to the fuzzy algebraic product and defined as:

$$
f_{a s}=1-\prod_{i=1}^{n}\left(1-f_{i}\right)
$$

The fuzzy $\gamma$ operation was defined in terms of the fuzzy algebraic product and the fuzzy algebraic sum as: 


$$
f=f_{a s}^{\gamma} \times f_{a p}^{1-\gamma}=\left(\prod_{i=1}^{n} f_{i}\right)^{\gamma} \times\left(1-\prod_{i=1}^{n}\left(1-f_{i}\right)\right)^{1-\gamma}
$$

where: $\gamma$ was a parameter chosen in the range [0,1]. In the fuzzy $\gamma$ operation, when $\gamma$ was 1 the combination was equal to the fuzzy algebraic sum, and when $\gamma$ was 0 the combination was equal to the fuzzy algebraic product.

\section{Results}

\subsection{Calculation Results}

The calculation results of entropy model and fuzzy logic model were shown in Table 2. These factors played a decisive role in the formation and development of such geohazards as landslide, collapse, etc., and were the dominant control conditions to geohazards.

\subsection{Susceptibility Zones}

\section{Entropy Model:}

A chi-square test also could be performed in order to test the statistical significance and effectiveness of the geohazard susceptibility test [12, 27, 31]. It reflected the differences between the observed geohazards and expected geohazards. For the hypothesis, the appearances of geohazard were purely due to the chance. In this case, the chi-square values of grid in observed geohazards and excepted geohazards with or without geohazard should be almost the same. If the chi-square values were different greatly, the hypothesis was wrong.

In this paper, the observed number of girds with and without geohazards for each of the four susceptibility classes was determined from the map, and the expected number of grids for the same was estimated from the observed values using excepted probabilities. The chi-square values of 162 geohazards and 182 geohazards without geohazards were much smaller than with geohazards respectively (Table 3). It suggested that the geohazards susceptibility map was considered statistically significant.

\section{Table 2. Results of Different Impact Factors with Entropy Model and Fuzzy Logic Model with Different Samples Including 162 and 182 Geohazards}

\begin{tabular}{|c|c|c|c|c|c|c|c|c|c|c|c|c|}
\hline \multirow[b]{2}{*}{ Types } & \multicolumn{2}{|c|}{162 geohazard } & \multicolumn{2}{|c|}{182 geohazards } & \multirow[b]{2}{*}{$\begin{array}{l}\text { Domain } \\
\text { pixels }\end{array}$} & \multirow[b]{2}{*}{$\begin{array}{l}\text { Percent of } \\
\text { domain } \\
(\%)\end{array}$} & \multicolumn{3}{|c|}{162 geohazards } & \multicolumn{3}{|c|}{182 geohazards } \\
\hline & $\begin{array}{l}\text { Geohaza } \\
\text { rd pixels }\end{array}$ & $\begin{array}{l}\begin{array}{l}\text { Percent of } \\
\text { geohazard } \\
(\%)\end{array} \\
\end{array}$ & $\begin{array}{l}\text { Geoha } \\
\text { zard } \\
\text { pixels }\end{array}$ & $\begin{array}{l}\begin{array}{l}\text { Percent of } \\
\text { geohazard } \\
\text { (\%) }\end{array} \\
\end{array}$ & & & $\begin{array}{l}\text { Entropy } \\
\text { values (I) }\end{array}$ & $\begin{array}{l}\text { Frequency } \\
\text { ratio (f) }\end{array}$ & $\begin{array}{l}\text { Fuzzy } \\
\text { membership } \\
\text { values (W) }\end{array}$ & $\begin{array}{l}\text { Entropy } \\
\text { values } \\
\text { (I) }\end{array}$ & $\begin{array}{l}\text { Frequenc } \\
\text { y ratio (f) }\end{array}$ & $\begin{array}{l}\text { Fuzzy } \\
\text { membershi } \\
\text { values (W) }\end{array}$ \\
\hline \multicolumn{13}{|l|}{ Elevation, $\mathrm{h}$-(m) } \\
\hline$h<600$ & & 28.478209 & & 25.740592 & 261130 & 3.915813 & 1.984116 & 7.272618 & 1.000000 & 1.8830463 & 6.573499 & 1.000000 \\
\hline $600<\mathrm{h} \leq 900$ & 13106 & 31.557910 & 13501 & 29.386414 & 1727928 & 25.911394 & 0.197141 & 1.217916 & 0.167466 & 0.1258496 & 1.134112 & 0.172528 \\
\hline $1000<\mathrm{h} \leq 1200$ & 5 & 17.854563 & 11415 & 24.846005 & 1722221 & 25.825814 & 115 & 46 & 0.095061 & -0.038678 & 61 & 0.146354 \\
\hline$h>1200$ & 9182 & 22.109319 & 9201 & 20.02699 & 2957324 & 44.346979 & -0.696045 & 3 & 0.068552 & -0.794964 & 0.451598 & 0.0687 \\
\hline \multicolumn{13}{|l|}{ Slope angles, p- $\left(0^{\circ}\right)$} \\
\hline (1) & & 818204 & & 22.101299 & 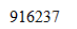 & 13.739564 & 075577 & 785506 & 0.981108 & 0.4753568 & 1.60 & 1.000000 \\
\hline $6<p \leq 1$ & & 10007 & & 42.396012 & 46 & (1) & 094649 & 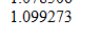 & 1.000000 & 0.4700000 & & 466 \\
\hline $30<\mathrm{p} \leq$ & & 11.203 & 4887 & 10.63 & 80 & 12.0 & & & & -0.12 & & 0.54813 \\
\hline \multirow{2}{*}{\multicolumn{13}{|c|}{$\begin{array}{l}\text { TSO, } p>30 \\
\text { TOBIA coefficient }(p)\end{array}$}} \\
\hline & & & & & & & & & & & & \\
\hline & 3797 & 9.142788 & & 10 & 2289449 & 34.331 & -1.323106 & 0.266307 & 0.127687 & -1.16276 & 0.312622 & 0.153634 \\
\hline 0. & & & 13801 & & & & & & & & & \\
\hline & & & 27211 & & 1941012 & 29.1 & 0.73 & 2.085 & 1.000000 & & & \\
\hline \multicolumn{13}{|l|}{$\frac{0.9<1.0}{\text { Geotechni }}$} \\
\hline Loosen roc & 1735 & 4.177703 & 2221 & 4.834251 & 30132 & 0.451849 & 2224169 & 9 & 1.000000 & 2.370134 & 26 & 00 \\
\hline ( & & & & & & & & & & & & 079268 \\
\hline & & & & & & & & & & & & \\
\hline & & & & & & & & & & & & \\
\hline \multirow{2}{*}{\multicolumn{13}{|c|}{$\begin{array}{l}\text { Hard acabonate eroc } \\
\text { Geological structh }\end{array}$}} \\
\hline & & & & & & & & & & & & \\
\hline influence scope of & 8432 & 20.303395 & 981 & 21.367782 & 1117837 & 16.762686 & 0.191633 & 1.211226 & 1.000000 & 0.2427289 & 1.274723 & 1.000000 \\
\hline \multirow{2}{*}{\multicolumn{13}{|c|}{ Distance to river or valley, $\mathrm{l}-\mathrm{m}$ ) }} \\
\hline & & & & & & & & & & & & \\
\hline $50 \triangleleft \leq 350 \mathrm{~m}$ & 16215 & 39.044065 & 16314 & 35.509218 & 8 & 20.361056 & 7 & 1.91 & 1.00 & 683 & 1.74 & 1.000000 \\
\hline $1 \leq 50 \mathrm{~m}, 350<1 \leq 550 \mathrm{~m}$ & & 20.252 & & 25.253 & 107 & 16.13 & & 1.23 & & & & 0.897513 \\
\hline $550<1 \leq 800$ & & $96<2>3$ & 501 & 10.90 & 93 & & -0.37 & 0.68 & 0.35 & -0.2 & 0.77872 & 0.446519 \\
\hline \multirow{2}{*}{\multicolumn{12}{|c|}{$3900100 \quad 49.496214$}} & 0.32818 \\
\hline & & & & & & & & & & & & \\
\hline the influ & 20 & .179629 & & & 2222 & 33 & & & & & 1.45 & 1.00 \\
\hline scope of road $(1<1 \leq 2)$ & 6397 & 15.4033 & 7012 & 15.26239 & 1586111 & 23.78 & -0.434 & 0.64 & 0.448 & -0.443 & 0.641688 & 0.442369 \\
\hline the influence scope of road $(1>2)$ & 15124 & 36.417048 & 16717 & 36.386392 & 2859676 & 42.88 & -0.163431 & 0.849225 & 0.58 & -0.164 & 0.84851 & 0.584949 \\
\hline primeval forest & & - & & 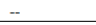 & - & 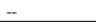 & - & -- & - & & & \\
\hline
\end{tabular}


Table 3. Results for the Chi-square Test with Different Samples

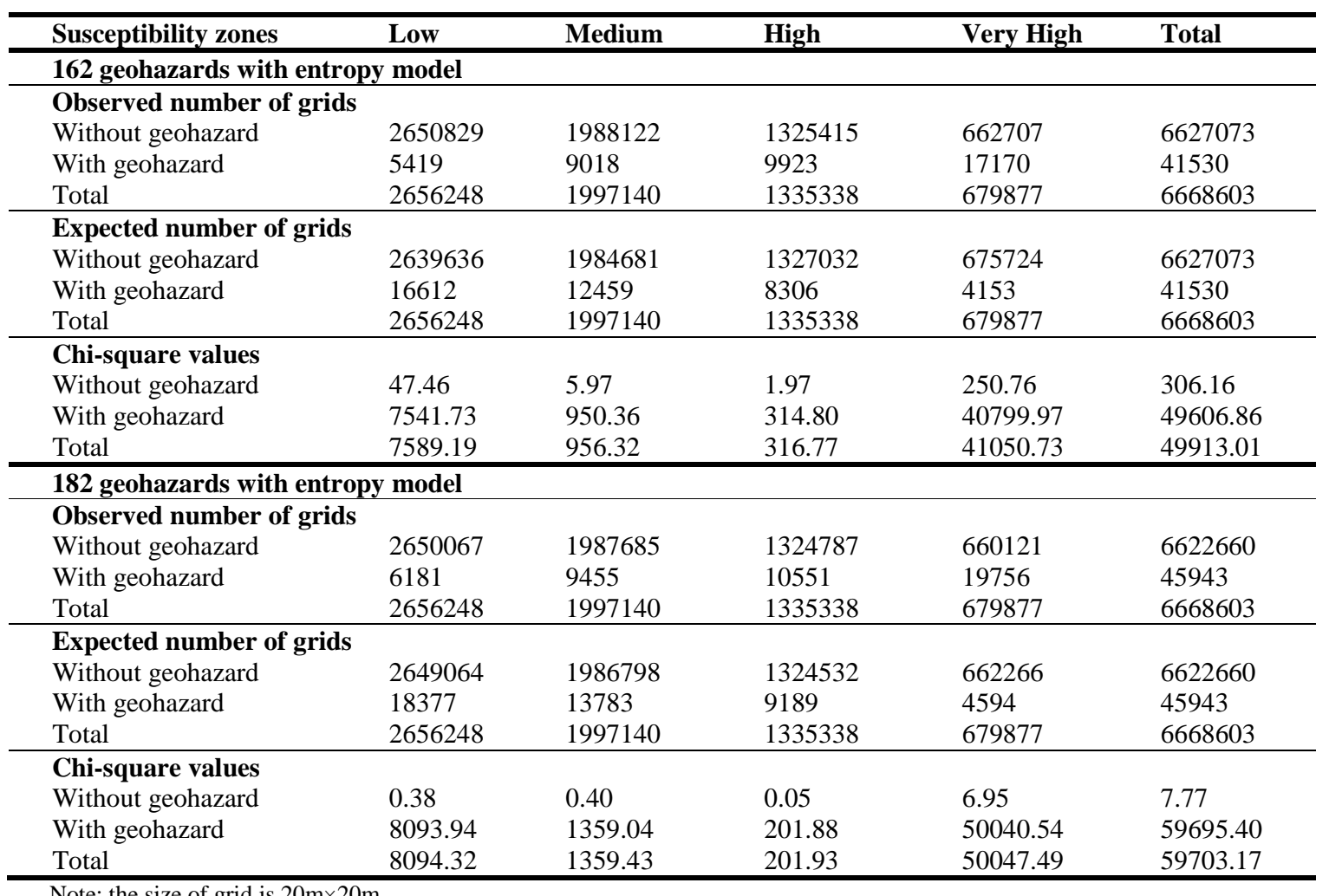

From Table 3, according to the chi-square test, it was found that chi-square values of 162 and 182 geohazards were almost the same, and the numerical difference was very small. In this case, it showed that there were no differences of statistical significance and effectiveness of the geohazard susceptibility assessment between 162 geohazards and 182 geohazards. The chi-square vale of 182 geohazards smaller than the value of 162 geohazards, it showed that the statistical significance and effectiveness of 182 geohazards was better than the ones of 162 geohazards.

20 geohazards were selected randomly in order to validate entropy model in Jianshi County. The effective result (162 geohazards) of entropy model was good and the confidence coefficient was 0.7499 [12]. The rationality and scientificness of the entropy model had been validated in western part of Hubei province. Therefore, on basis of the same concept and mathematical model, the analysis of geohazard susceptibility assessment with 182 geohazards was rationality and scientific. In this paper, the 182 geohazards of the whole county were considered as samples and the susceptibility zonation was calculated with entropy model. The confidence coefficient was 0.6863 , smaller than the value of 162 geohazards.

\section{Fuzzy Logic Model:}

In this paper, the frequency ratio was calculated for all types of geohazards background impact factors according to the areas of the geohazards in the impact factors. The fuzzy membership values were calculated by normalizing the ratio values into the range of $0 \sim 1[36]$. The results are shown in Table 4.

The fuzzy membership values were weighted as the different classes of impact factors, and the geohazard susceptibility index values of each grid were calculated according to the equation (7) with the spatial analysis function of ArcGIS. In order to find out the best methods, the parameter $\gamma$ in equation (7) were calculated as $0.1,0.2,0.3,0.4,0.5,0.6,0.7$, 
0.8, 0.9 and 1.0.The operator enable a compromise between the increasing tendencies of fuzzy SUM and the decreasing effect of the fuzzy Product [26, 37]. The statistics of the geohazards susceptibility index values for 162 geohazards and 182 geohazards were shown in Table 4.

Table 4. Statistics of the Geohazard Susceptibility Index Values

\begin{tabular}{llllll}
\hline$\gamma$ & Max & Min & Mean & Std dev. & AUC(\%) \\
\hline $\mathbf{1 8 2}$ geohazards & & & & & \\
0 & 1.000000 & 0.963567 & 0.995499 & 0.008471 & 33.77 \\
0.1 & 0.886340 & 0.352895 & 0.484294 & 0.065780 & 68.03 \\
0.2 & 0.785598 & 0.129244 & 0.239678 & 0.067145 & 67.96 \\
0.3 & 0.696307 & 0.047334 & 0.120817 & 0.053450 & 67.58 \\
0.4 & 0.617164 & 0.017336 & 0.062106 & 0.039000 & 67.05 \\
0.5 & 0.547017 & 0.006349 & 0.032595 & 0.027464 & 65.81 \\
0.6 & 0.484843 & 0.002325 & 0.017483 & 0.019091 & 64.11 \\
0.7 & 0.429736 & 0.000852 & 0.009591 & 0.013247 & 61.82 \\
0.8 & 0.380892 & 0.000312 & 0.005384 & 0.009230 & 68.64 \\
0.9 & 0.337600 & 0.000114 & 0.003093 & 0.006478 & 68.69 \\
1.0 & 0.299228 & 0.000042 & 0.001818 & 0.004587 & 66.52 \\
Entropy model & 5.403262 & -3.472008 & -0.687634 & 1.269101 & 68.63 \\
\hline $\mathbf{1 6 2}$ geohazards & & & & \\
0 & 1.000000 & 0.994237 & 0.998833 & 0.001840 & 57.88 \\
0.1 & 0.968327 & 0.425206 & 0.530041 & 0.067828 & 68.65 \\
0.2 & 0.848219 & 0.181848 & 0.285806 & 0.078370 & 69.00 \\
0.3 & 0.718327 & 0.077771 & 0.156905 & 0.070049 & 68.75 \\
0.4 & 0.638217 & 0.033260 & 0.087887 & 0.057418 & 69.05 \\
0.5 & 0.552982 & 0.014224 & 0.050335 & 0.045599 & 68.53 \\
0.6 & 0.489213 & 0.006083 & 0.029540 & 0.035983 & 68.74 \\
0.7 & 0.431872 & 0.002602 & 0.017797 & 0.028599 & 68.56 \\
0.8 & 0.386215 & 0.001113 & 0.011024 & 0.023066 & 68.97 \\
0.9 & 0.338019 & 0.000476 & 0.007028 & 0.018949 & 66.18 \\
1.0 & 0.310287 & 0.000204 & 0.004614 & 0.015876 & 65.67 \\
Entropy model & 4.890346 & -3.986272 & -0.722090 & 1.179769 & 74.99 \\
\hline
\end{tabular}

The AUC (area under the curve) values mean the confidence coefficients of different models. From Table 4, the AUC values of entropy model were higher than the ones of fuzzy logic model. The differences between 162 geohazards and 182 geohazards conformed to the more the number of samples in statistical analysis, the lower the degree of confidence coefficient. In some degree, the differences mean the entropy model was unstable and the accuracy of entropy model depended on the characters of samples, including the spatial and attributive characteristics.

The AUC values of 162 geohazards were higher than the values of 182 geohazards in fuzzy logic model. In order to analysis the stability of the fuzzy logic model, the authors compared the AUC when the parameter $\gamma$ in equation (7) were calculated as $0,0.2,0.4$, 0.6, 0.8 and 1.0 (Figure 2). From the figures, it obviously showed the curves of 162 geohazards with small contact ratio and the curves of 182 geohazards with good contact ratio except $\gamma=1.0$. It suggested that the stable of fuzzy logic model was better if the geohazards were enough. On basis of the above analysis, the stable of fuzzy logic model was good for the susceptibility analysis. 


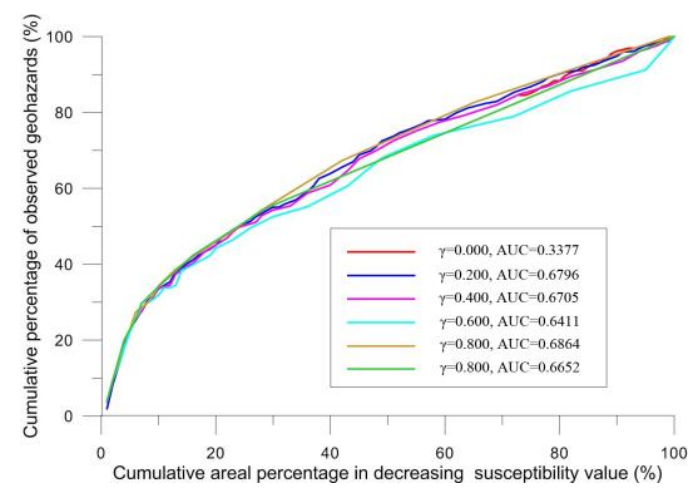

a

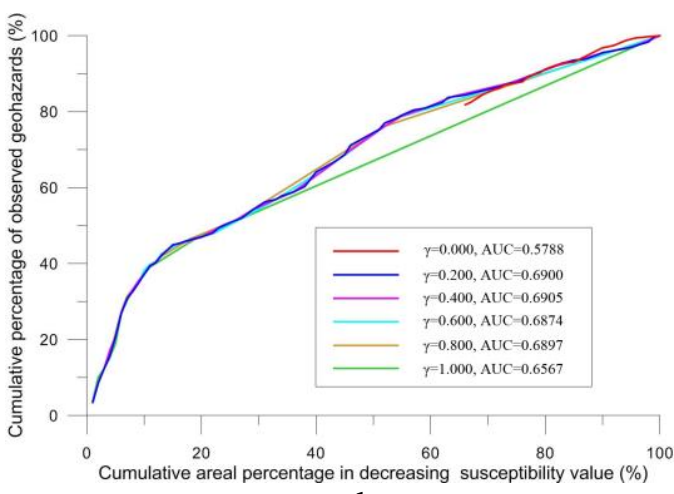

b

Figure 2. Success Rate Curves of Fuzzy Logic Models

(a: including 162 geohazards, b: including 182 geohazards)

Not only 162 geohazards but also 182 geohazards in fuzzy logic model, when $\gamma=0.2$, the AUC values were almost the highest and the standard deviation were the biggest values (Table 4). In statistics, when the value of standard deviation was bigger, it suggested that the data contained a greater amount of information, and the result was better representative and more reliable. In this case, the authors considered when the $\gamma$ $=0.2$, the fuzzy logic model was the best in the study. In this case, the authors used $\gamma=0.2$ to complete the susceptibility assessment with fuzzy logic model. The results of 162 geohazards and 182 geohazards were also classified into four classes, including low, medium, high and very high susceptibility zones. Chi-square test also could be performed in order to test the statistical significance and effectiveness of the geohazard susceptibility test $[5,12,27]$.

In this paper, the chi-square values of 162 geohazards and 182 geohazards with geohazards were much bigger than without geohazards respectively. It showed that the geohazards susceptibility map was considered statistically significant $[5,12]$. The chisquare vale of 182 geohazards smaller than the value of 162 geohazards, it suggested that the statistical significance and effectiveness of 182 geohazards was better than the ones of 162 geohazards (Table 5).

Table 5. Results for the Chi-square Test with Different Samples

\begin{tabular}{|c|c|c|c|c|c|}
\hline Susceptibility zones & Low & Medium & High & Very High & Total \\
\hline \multicolumn{6}{|c|}{162 geohazards with fuzzy logic model } \\
\hline \multicolumn{6}{|c|}{ Observed number of grids } \\
\hline Without geohazard & 2648325 & 1986047 & 1328283 & 664418 & 6627073 \\
\hline With geohazard & 7923 & 11093 & 7055 & 15459 & 41530 \\
\hline Total & 2656248 & 1997140 & 1335338 & 679877 & 6668603 \\
\hline \multicolumn{6}{|c|}{ Expected number of grids } \\
\hline Without geohazard & 2650829.2 & 1988121.9 & 1325414.6 & 662707 & 6627072.7 \\
\hline With geohazard & 16612 & 12459 & 8306 & 4153 & 41530 \\
\hline Total & 2656248 & 1997140 & 1335338 & 679877 & 6668603 \\
\hline \multicolumn{6}{|l|}{ Chi-square values } \\
\hline Without geohazard & 2.37 & 2.17 & 6.21 & 4.42 & 15.16 \\
\hline With geohazard & 4544.83 & 149.77 & 188.42 & 30779.11 & 35662.12 \\
\hline Total & 4547.20 & 151.93 & 194.63 & 30783.53 & 35677.28 \\
\hline \multicolumn{6}{|c|}{182 geohazards with fuzzy logic model } \\
\hline \multicolumn{6}{|c|}{ Observed number of grids } \\
\hline Without geohazard & 2650067 & 1987685 & 1324787 & 660121 & 6622660 \\
\hline With geohazard & 6181 & 9455 & 10551 & 19756 & 45943 \\
\hline Total & 2656248 & 1997140 & 1335338 & 679877 & 6668603 \\
\hline \multicolumn{6}{|c|}{ Expected number of grids } \\
\hline Without geohazard & 2649064 & 1986798 & 1324532 & 662266 & 6622660 \\
\hline With geohazard & 18377 & 13783 & 9189 & 4594 & 45943 \\
\hline Total & 2656248 & 1997140 & 1335338 & 679877 & 6668603 \\
\hline \multicolumn{6}{|l|}{ Chi-square values } \\
\hline Without geohazard & 3.04 & 0.12 & 0.67 & 8.60 & 12.44 \\
\hline With geohazard & 3796.74 & 632.25 & 49.58 & 24596.63 & 29075.20 \\
\hline Total & 3799.78 & 632.37 & 50.25 & 24605.23 & 29087.63 \\
\hline
\end{tabular}




\subsection{Results and Discussions}

\section{Results:}

According to analysis results of fuzzy logic model, in this paper, the entropy model and fuzzy logic model $(\gamma=0.2)$ were employed to calculate the susceptibility values for the Jianshi county with ArcGIS spatial analysis function. All influencing factors were weighted based on calculation results of entropy model and fuzzy logic model [5, 6, 9]. The spatial analysis of entropy model was completed based on ArcGIS, obtaining the distribution range of unit value. The values of susceptibility assessment were shown in table 6 and figure 3. Statistical data of 162 geohazards showed that the Eigen-values of entropy model were 4.1340 and 1.1950 which were bigger than the ones of fuzzy model (3.7224 and 1.1950) in very high and high susceptibility zones respectively. The data of 182 geohazards had the same characters which the values of entropy model (4.1250 and 1.2580) were bigger than the values of fuzzy logic model (3.3317 and 1.0735) in very high and high susceptibility zones respectively. The unit geohazards Eigen-values of very high susceptibility zones of geohazards with entropy model were greater than the Eigenvalues with fuzzy logic model.

\section{Table 6. Correlation Table of Geohazard Susceptibility Zonation and} Geohazards

\begin{tabular}{|c|c|c|c|c|c|c|}
\hline \multirow{2}{*}{ Susceptibility } & \multirow{2}{*}{$\begin{array}{l}\text { Susceptibility } \\
\text { values }\end{array}$} & \multirow{2}{*}{$\begin{array}{l}\text { Numbe } \\
\mathbf{r} \text { of } \\
\text { grid }\end{array}$} & \multirow{2}{*}{$\begin{array}{l}\begin{array}{l}\text { Percentage } \\
\text { of area }\end{array} \\
\mathbf{a}(\%) \\
\end{array}$} & \multirow{2}{*}{$\begin{array}{l}\text { Grid } \\
\text { number of } \\
\text { geohazards }\end{array}$} & \multirow{2}{*}{$\begin{array}{l}\text { Percentage of } \\
\text { geohazards } \\
\text { b }(\%)\end{array}$} & \multirow{2}{*}{$\begin{array}{l}\text { Unit } \\
\text { geohazard } \\
\text { Eigen-value } \\
\text { b/a } \\
\end{array}$} \\
\hline & & & & & & \\
\hline \multicolumn{7}{|l|}{162 geohazards } \\
\hline \multicolumn{7}{|l|}{ Entropy model } \\
\hline Very High & $0.7726 \sim 4.9862$ & 679877 & 10 & 17170 & 41.34 & 4.1340 \\
\hline High & $-0.1539 \sim 0.7726$ & 1335338 & 20 & 9923 & 23.90 & 1.1950 \\
\hline Medium & $-1.1833 \sim-0.1539$ & 1997140 & 30 & 9018 & 21.71 & 0.7237 \\
\hline Low & $-3.0241 \sim-1.1833$ & 2656248 & 40 & 5419 & 13.05 & 0.3263 \\
\hline Total & & 6668603 & 100 & 41530 & 100 & 1.0000 \\
\hline \multicolumn{7}{|c|}{ Fuzzy logic model } \\
\hline Very High & $0.3928 \sim 0.8482$ & 679877 & 10 & 15459 & 37.22 & 3.7224 \\
\hline High & $0.2969 \sim 0.3928$ & 1335338 & 20 & 7055 & 16.99 & 0.8494 \\
\hline Medium & $0.2490 \sim 0.2969$ & 1997140 & 30 & 11093 & 26.71 & 0.8904 \\
\hline Low & $0.1818 \sim 0.2490$ & 2656248 & 40 & 7923 & 19.08 & 0.4769 \\
\hline Total & & 6668603 & 100 & 41530 & 100 & 1.0000 \\
\hline \multicolumn{7}{|l|}{182 geohazards } \\
\hline \multicolumn{7}{|l|}{ Entropy model } \\
\hline Very High & $0.8079 \sim 5.0921$ & 679877 & 10 & 18952 & 41.25 & 4.1250 \\
\hline High & $-0.1691 \sim 0.8079$ & 1335338 & 20 & 11559 & 25.16 & 1.2580 \\
\hline Medium & $-1.1829 \sim-0.1691$ & 1997140 & 30 & 9593 & 20.88 & 0.6960 \\
\hline Low & $-3.1473 \sim-1.1829$ & 2656248 & 40 & 5839 & 12.71 & 0.3178 \\
\hline Total & & 6668603 & 100 & 45943 & 100 & 1.0000 \\
\hline \multicolumn{7}{|c|}{ Fuzzy logic model } \\
\hline Very High & $0.3215 \sim 0.7856$ & 679877 & 10 & 15224 & 33.14 & 3.3137 \\
\hline High & $0.2549 \sim 0.3215$ & 1335338 & 20 & 9864 & 21.47 & 1.0735 \\
\hline Medium & $0.2087 \sim 0.2549$ & 1997140 & 30 & 10831 & 23.57 & 0.7858 \\
\hline Low & $0.1292 \sim 0.2087$ & 2656248 & 40 & 10024 & 21.82 & 0.5455 \\
\hline Total & & 6668603 & 100 & 45943 & 100 & 1.0000 \\
\hline
\end{tabular}

The very high and high susceptibility zones of 162 geohazards and 182 geohazards were about $65.24 \%$ and $66.41 \%$ of the total area employing entropy model and about $54.21 \%$ and $54.61 \%$ of the total area employing fuzzy logic model. The area percentages of entropy model were higher than the percentages of fuzzy logic model and the area 
percentages of 162 geohazards were lower than the percentages of 182 geohazards respectively. According to the table, the entropy model was better than the fuzzy logic model, especially highlight the concentrated area of geohazards. Obviously, the results of different models were almost same in the space, but different in some areas.
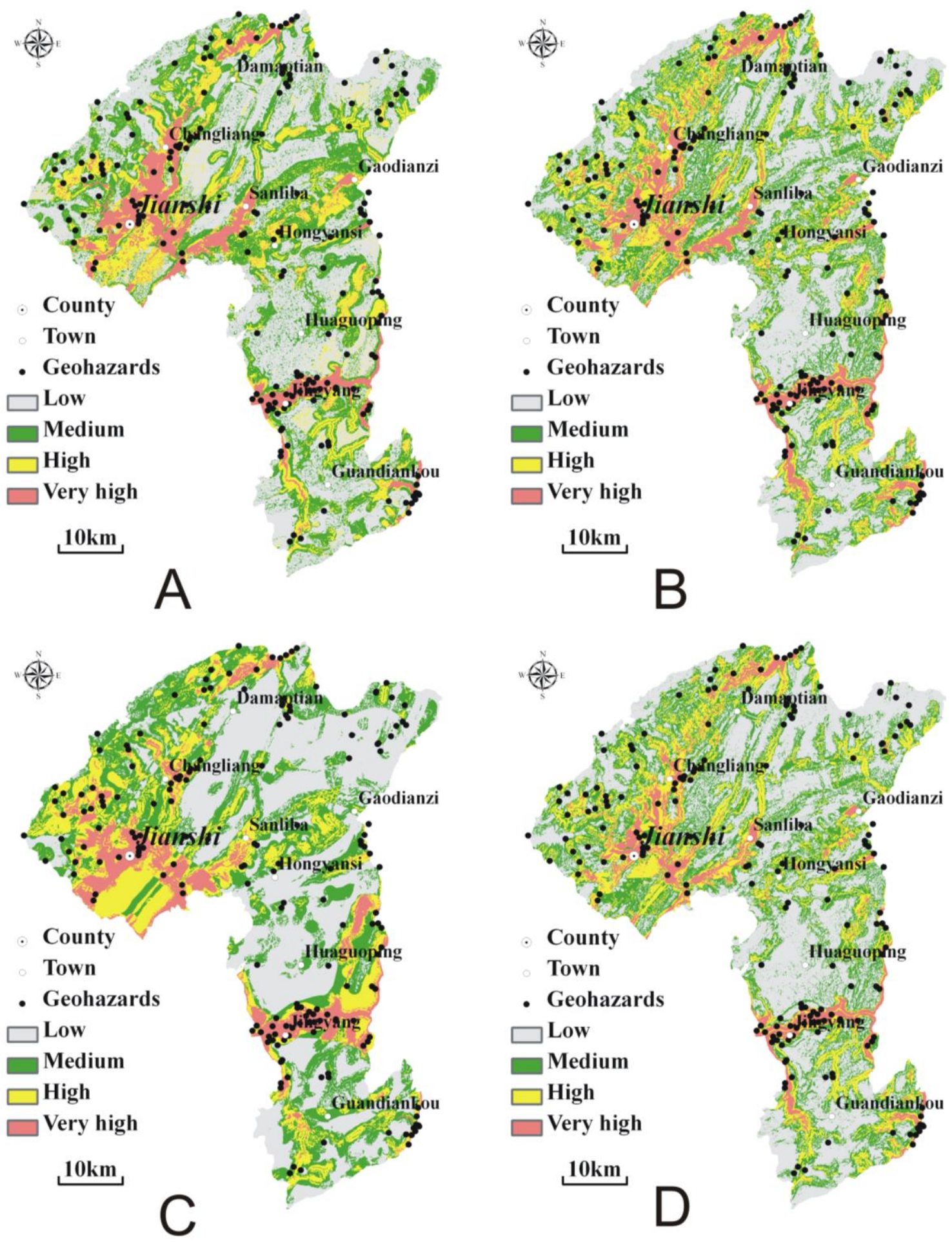

Figure 3. Results of Fuzzy Logic and Entropy Models with Different Numbers of Geohazards 
(A: result of fuzzy logic model with 162 geohazards; B: result of fuzzy logic model with 182 geohazards; C: 1result of entropy model with 162 geohazards; D: result of entropy model with 182 geohazards)

\section{Comparison of Entropy and Fuzzy Logic Model:}

In this paper, fuzzy logic model and entropy model were employed to complete the geohazard susceptibility zonation in Jianshi County of Qingiiang River Basin. The results of different models were almost the same in the space, except some small areas. The two models were useful for the analysis of geohazard susceptibility.

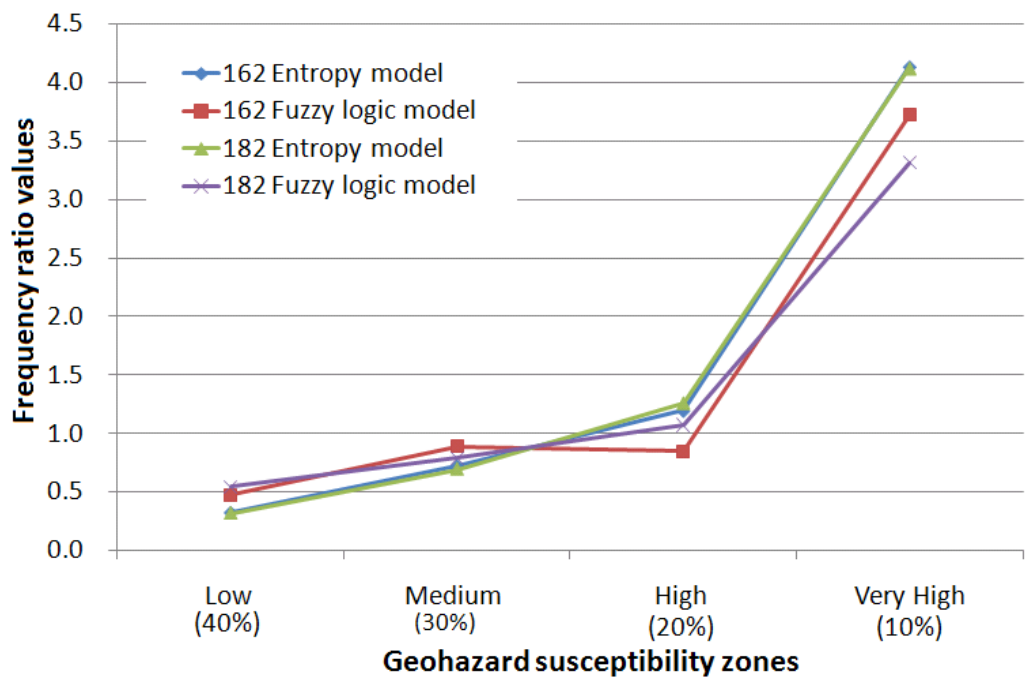

Figure 4. Frequency Ratio Plots of Geohazard Susceptibility Zones of Fuzzy Logic Model and Entropy Model

From Table 6 and Figure 4, statistical data showed that the frequency ratio values of 162 geohazards were bigger than the ones of 182 geohazards and the ones of entropy model were bigger than the ones of fuzzy logic model in very high and high susceptibility zones except the frequency ratio value of 162 geohazards smaller than the one of 182 geohazards with fuzzy logic model. However, the characters of frequency ratio values were inversed in the low and medium susceptibility zones. Totally, the frequency ratio values of fuzzy logic model and entropy model were almost the same in each susceptibility zone respectively.

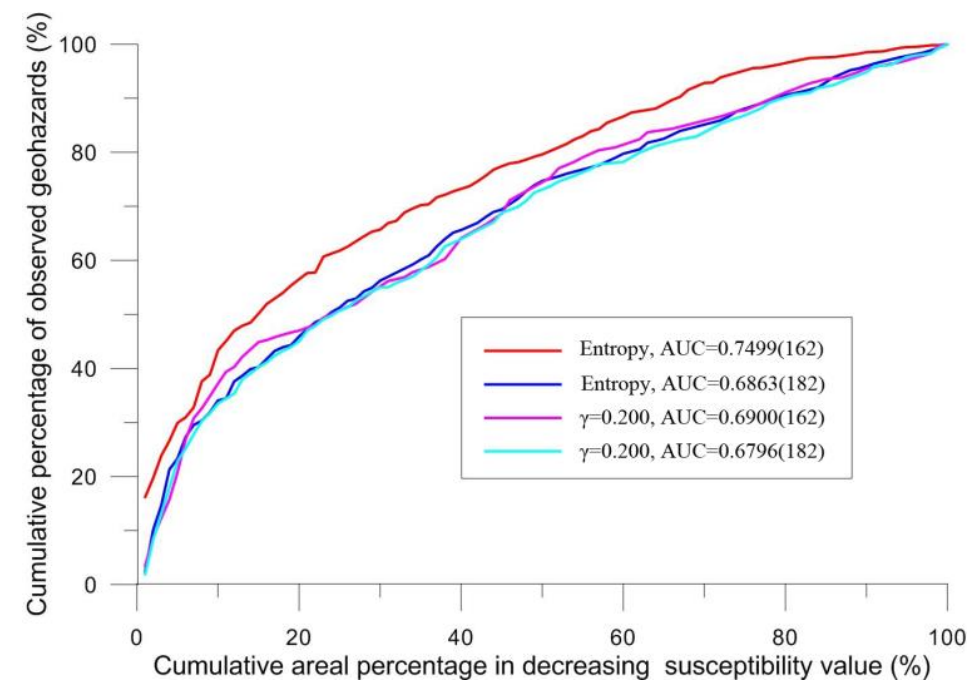

Figure 5. Success-rate Curves of Fuzzy Logic and Entropy Models 
The AUC values of 162 geohazards were bigger than the ones of 182 geohazards. The curve of 162 geohazards was above the one of 182 geohazards, obviously the two curves of entropy model much different. In this case, it suggested that the entropy model was not stable with different samples (Fig.5). However, the two curves of fuzzy logic model were almost the same. It suggested that the fuzzy logic model was stable and not influenced by the number of samples. Basing on the above analysis, the fuzzy logic model was suitable for the geohazard susceptibility zonation in Jianshi County. The two models of geohazard susceptibility zonation would provide references of preliminary development planning purposes.

\section{Conclusions}

In this study, the entropy model and fuzzy logic model were based on the statistical analysis with ArcGIS software. The models were both quantitative analysis and assessment of geohazard susceptibility zonation. The authors used the entropy model and fuzzy logic model to finish the geohazard susceptibility zonation with different numbers of geohazards (162 geohazards and 182 geohazards). Generally, the results of different geohazards with the two models were almost the same in the space. It suggested that the two models were useful for Jianshi County. However, there were different advantages and disadvantages in the two models.

In the case of entropy modeling, it could accurately analyze the characteristics of geohazards on different influence factors according to the statistical data of geohazards [11-12]. The entropy model would be influenced by the number and spatial character of geohazards. However, it analyzed the probability of geohazards in terms of their formation mechanisms and obtains the major controlling factors quantitatively.

The fuzzy logic model could be used to complete the geohazard susceptibility zonation with a few geohazards. In some degree, it would get a general relationship between the geohazards and impact factors. According to the analysis process, it was found that the fuzzy $\gamma$ operation was the best and most useful when $\gamma$ was 0.20 . It was easy to find out the determine impact factors.

Generally, on basis of the formation mechanisms of geohazards, the fuzzy logic model and entropy model were useful for the geohazard susceptibility zonation which was consistent with the field investigations.

\section{Acknowledgements}

This paper was supported Qingjiang River Geological Disasters Detailed Survey, China Geological Survey (No.1212010814008) and the National Natural Science Foundation of China (No.41372321).

\section{References}

[1] J. Remondo, A. González, JR. Díaz de Terán, A. Cendrero, A. Fabbri and CF. Cheng, "Validation of landslide susceptibility maps: examples and applications from a case study in Northern Spain", Nat Hazards, vol. 30, no. 3, (2003), pp. 437-449.

[2] GC. Ohlmacher and JC. Davis, "Using multiple logistic regression and GIS technology to predict landslide hazard in Northeast Kansas, USA", Eng. Geol., vol. 69, nos. 3-4, (2003), pp. 331-343.

[3] CZ. Liu and YH. Liu, "Early warning theory for regional geohazards and design of explicit statistical system", Hydrogeol. Eng. Geol., vol. 6, (2008), pp. 109-125.

[4] KC. Gao, P. Cui, CY. Zhao and FQ. Wei, "Landslide hazard evaluation of Wanzhou based on GIS information value method in the Three Gorges reservoir", J Rock Mech Eng., vol. 25, no. 5, (2006), pp. 991-996.

[5] P. Kayastha, MR. Dhital and F. De Smedt, "Landslide susceptibility mapping using the weight of evidence method in the Tinau watershed", Nepal. Nat Hazards, vol. 63, no. 2, (2012), pp. 479-498.

[6] SM. Bijukchhen, P. Kayastha and MR. Dhital, "A comparative evaluation of heuristic and bivariate statistical modelling for landslide susceptibility mappings in Ghurmi-Dhad Khola, east Nepal", Arab J Geosci., vol. 6, no. 8, (2013), pp. 2727-2743. 
[7] F. Guzzetti, P. Reichenbach, M. Cardinali, M. Galli and F. Ardizzone, "Probabilistic landslide hazard assessment at the basin scale", Geomorphology, vol. 72, (2005), pp. 272-299.

[8] F. Guzzetti, P. Reichenbach, F. Ardizzone, M. Cardinali and M. Galli, "Estimating the quality of landslide susceptibility models, Geomorphology, vol. 81, (2006), pp. 166-184.

[9] P. Kayastha, MR. Dhital and F. De Smedt, "Evaluation and comparison of GIS based landslide susceptibility mapping procedures in Kulekhani watershed", Nepal. J Geol. Soc. India, vol. 81, (2013), pp. 219-231.

[10] J. Chacon, C. Irigaray, T. Fernandez and R. El Hamdouni, "Engineering geology maps: landslides and geographical information systems", B Eng Geol Environ, vol. 65, (2006), pp. 341-411.

[11] N. Wang, K. Peng, Q. Li, X. Zhao, Y. Li and J. He, "Quantitative evaluation of geological disaster liability based on RS \& GIS analysis: A case study of Wufeng County, Hubei Province", Earth Sci Front vol. 19, no. 6, (2012), pp. 221-229.

[12] N. Wang, T. Shi, K. Peng, W. Zhang and X. Jin, “ Assessment of geohazard susceptibility based on RS and GIS analysis in Jianshi County of the Three Gorges Reservoir", China. Arab J Geosci. (2013) (doi: 10.1007/s12517-013-1196-7)

[13] Y. Zhang, ZF. Yang and W. Li, "Analyses of urban ecosystem based on information entropy", Ecol Model, vol. 197, nos. 1-2, (2006), pp. 1-12.

[14] KT. Lee and JY. Ho, "Prediction of landslide occurrence based on slope-Instability Analysis and Hydrolo-gical Model Simulation”, J. Hydrol., vol. 375, nos. 3-4, (2009), pp. 489-497.

[15] RM. Srivastava and O. Leuangthong, "On maximizing spatial entropy”, Ninth International Geostatistics Congress, (2012).

[16] RL. Chen and ZX. Zeng, "Method of entropy coefficient to evaluate the surrounding rock stability of underground engineering", J Huaqiao University (Natural Science), vol. 29, no. 3, (2008), pp. 443-446.

[17] RC. Tewari, DP. Singh and ZA. Khan, "Application of Markov chain and entropy analysis to lithologic succession - an example from the early Permian Barakar Formation", Bellampalli coalfield, Andhra Pradesh, India. J Earth Syst. Sci., vol. 118, no. 5, (2009), pp. 583-596.

[18] L. Pantelidis, "Rock slope stability assessment through rock mass classification system", Int. J. Rock Mech Min, vol. 46, no. 2, (2009), pp. 315-325.

[19] DX. Chen and DA. Liu, "Safety entropy based on slope stability analysis", J. Eng. Geol., vol. 18, no. 6, (2010), pp. 851-856.

[20] CY. Tseng and CC. Chen, "Entropic component analysis and its application in geological data", Comput. Geosci., vol. 37, no. 11, (2011), pp. 1777-1782.

[21] JF. Wellmann and K. Regenauer-Lieb, "Uncertainties have a meaning: Information entropy as a quality measure for 3-D geological models, Tectonophysics, (2012), pp. 526-529, 207-216.

[22] JF. Wellmann and K. Regtenauer-Lieb, "Effect of geological data quality on uncertainties in geological models and subsurface flow fields", Thirty-Seventh Workshop on Geothermal Reservoir Engineering, (2012).

[23] QB. Rong, HJ. Zhang and FS. Wang, "Entropy-based set pair analysis model on geological disaster risk for military engineering", Eng., vol. 4, (2012), pp. 76-82.

[24] S. Lee, "Application and verification of fuzzy algebraic operators to landslide susceptibility mapping", Environ., Geol., vol. 52, (2007), pp. 615-623.

[25] MH. Tangestani, "A comparative study of Dempster-Shafer and fuzzy models for landslide susceptibility mapping using a GIS: An experience from Zagros Mountains", SW Iran. J Asian Earth Sci., vol. 35, (2009), pp. 66-73.

[26] D. Tien Bui, B. Pradhan, O. Lofman, I. Revhaug and OB Dick, "Spatial prediction of landslide hazards in Hoa Binh province (Vietnam): A comparative assessment of the efficacy of evidential belief functions and fuzzy logic models, Catena, vol. 96, (2012), pp. 28-40.

[27] S. Sarkar and DP. Kanungo, "An integrated approach for landslide susceptibility mapping using remote sensing and GIS", Photogramm. Eng. Rem. S ., vol. 70, (2004), pp. 617-625.

[28] S. Lee and U. Choi, "Development of GIS-based geological hazard information system and its application for landslide analysis in Korea", Geosci. J., vol. 7, no. 3, (2003), pp. 243-252.

[29] WQ. Cong, M. Pan, TF. Li, XZ. Wu and GX. Lv, "Key research on landslide and debris flow hazard zonation based on GIS", Earth Sci Front, vol. 13, no. 1, (2006), pp. 185-190.

[30] SS. Hou, A. Li, PG. Zhou and R. Wang, "Regional landslide susceptibility assessment using bivariate statistic method-A case study of Yucheng District, Yaan City, Sichuan Povince", Hydrogeol Eng Geol vol. 33, no. 1, (2006), pp. 1-4.

[31] P. Kayastha, "Application of fuzzy logic approach for landslide susceptibility mapping in Garuwa subbasin", east Nepal. Front Earth Sci., vol. 6, no. 4, (2012), pp. 420-432.

[32] CZ. Liu, TF. Li, MS. Wen, XP. Wang and B. Yang, "Assessment and early warning on geohazards in the Three Gorges Reservoir region of Changjiang River", Hydrogeol Eng Geol, vol. 4, (2004), pp. 9-19.

[33] SC. Chen, JW. Ferng, YT. Wang, TY. Wu and JJ. Wang, "Assessment of disaster resilience capacity of hillslope communities with high risk for geological hazards", Eng. Geol., vol. 98, (2008), pp. 86-101.

[34] GF. Bonham-Carter, "Geographic Information Systems for Geoscientists: Modelling with GIS", Pegamon Press (1994).

[35] HJ. Zimmermann, "Fuzzy Set Theory - and Its Applications”, Springer (1991). 
[36] B. Pradhan, "Manifestation of an advanced fuzzy logic model coupled with geoinformation techniques to landslide susceptibility mapping and their comparison with logistic regression modelling”, Environ Ecol Stat, vol. 18, (2011), pp. 471-493.

[37] D. Malins and G. Metternicht, "Assessing the spatial extent of dryland salinity through fuzzy modeling", Ecol Model, vol. 193, (2006), pp. 387-411.

\section{Author}

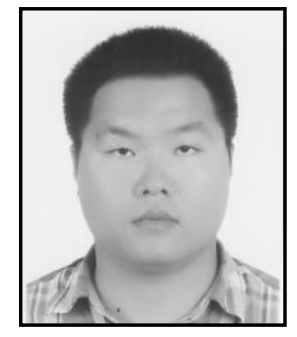

Ningtao Wang, He received his ME. Sc. in Water Resources and Hydrology (2006) from China University of Geosciences. Now he is full assistant research fellow of geology at Wuhan Center of Geological Survey. Since 2008 he is a member of CPGIS. His current research interests include different aspects of geohazard model and GIS. 
International Journal of $u-$ and e- Service, Science and Technology Vol.8, No.4 (2015) 